\title{
Unusual Double Beckmann Fragmentation Reaction under Physiological Conditions
}

\author{
Lin-Na Xie, ${ }^{\dagger}$ Chun-Hua Huang, ${ }^{\dagger}$ Dan $\mathrm{Xu}^{\dagger}{ }^{\dagger}$ Feng $\mathrm{Li}^{\dagger}{ }^{\dagger}$ Jun-Ge Zhu, ${ }^{\dagger}$ Chen Shen, ${ }^{\dagger}$ Bo Shao, ${ }^{\dagger}$

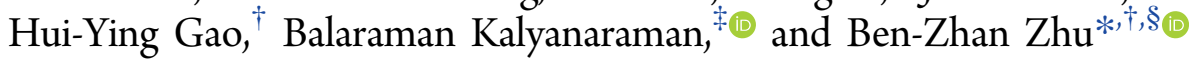

${ }^{\dagger}$ State Key Laboratory of Environmental Chemistry and Ecotoxicology, Research Center for Eco-Environmental Sciences, University of Chinese Academy of Sciences, Beijing 100085, P. R. China

${ }^{\ddagger}$ Department of Biophysics, Medical College of Wisconsin, Milwaukee, Wisconsin 53226, United States

${ }^{\S}$ Linus Pauling Institute, Oregon State University, Corvallis, Oregon 97331, United States

Supporting Information

ABSTRACT: Pyridinium aldoximes, which are best-known as therapeutic antidotes for organophosphorus chemical warfare nerve-agents and pesticides, have been found to markedly detoxify polyhalogenated quinones, which are a class of carcinogenic intermediates and recently identified disinfection byproducts in drinking water. However, the exact chemical mechanism underlying this detoxication remains unclear. Here we demonstrate that pralidoxime can remarkably facilitate the dechlorination/hydroxylation of the highly toxic tetrachloro1,4-benzoquinone in two-consecutive steps to generate the much less toxic 2,5-dichloro-3,6-dihydroxy-1,4-benzoquonine, with rate enhancements of up to 180000 -times. On the

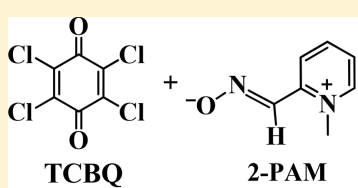

TCBQ 2-PAM $\stackrel{\begin{array}{l}\text { Nucleophilic } \\ \text { Substitution }\end{array}}{\stackrel{\mathrm{Cl}^{-}}{\longrightarrow}}$ (1st Beckmann $\downarrow \begin{aligned} & \text { 1st Beckmann } \\ & \text { Fragmentation }\end{aligned}$<smiles>N#Cc1cccc[n+]1CCCCCC(=O)O</smiles><smiles>N#C[C+]1C=CC=C[C@H]1C#N</smiles>
contrary, no accelerating effect was noticed with $O$-methylated pralidoxime. The major reaction product from pralidoxime was identified as its corresponding nitrile (2-cyano-1-methylpyridinium chloride). Along with oxygen-18 isotope-labeling studies, a reaction mechanism was proposed in which nucleophilic substitution coupled with an unprecedented double Beckmann fragmentation reaction was responsible for the dramatic enhancement in the detoxification process. This represents the first report of an unusually mild and facile Beckmann-type fragmentation that can occur under normal physiological conditions in two-consecutive steps. The study may have broad biomedical and environmental significance for future investigations of aldoxime therapeutic agents and carcinogenic polyhalogenated quinones.

\section{INTRODUCTION}

Polyhalogenated quinones are a group of reactive intermediates which can cause various harmful consequences in vivo, such as acute nephrotoxicity, hepatoxicity, and carcinogenesis. ${ }^{1,2}$ Pentachlorophenol (PCP) has been extensively used for wood preservation. In addition, PCP was used to prevent snail fever as a snail-killing compound in China and other developing countries. The U.S. EPA has identified that at least $20 \%$ of National Priorities List sites are contaminated with PCP, and the International Association for Research on Cancer (IARC) has recently considered PCP as a Group-I environmental carcinogen. ${ }^{3,4}$ During the oxidation and destruction processes for PCP and other polychlorinated aromatic compounds via different chemical and enzymatic systems, tetrachloro-1,4-benzoquinone (TCBQ) has been generated as a reactive and transient intermediate or final product. ${ }^{3,5-8}$ Recently, TCBQ was detected as one of many disinfection quinoid byproducts in chlorination of drinking and swimming pool waters. ${ }^{9,10}$ TCBQ was often used as a powerful oxidizing or dehydrating agent in organic synthesis.
Pyridinium aldoximes have been used as acetylcholinesterase activators since the $1950 \mathrm{~s}$ for the medical treatment of poisoning with organophosphorus nerve agents and pesticides. More than 300000 fatalities every year are due to organophosphorus pesticide poisoning worldwide, resulting in a serious public health problem. In addition, organophosphorus nerve agents remain a persistent threat to the public due to terrorist attacks and armed conflicts. Aldoximes possess high nucleophilicity that can displace the phosphyl group from the catalytic serine to restore catalytic activity of the enzyme. ${ }^{11-16}$

In recent years, researchers have devoted enormous efforts to the synthesis and development of new compounds as potential antidotes. Only four pyridinium aldoximes (i.e., pralidoxime or 2-PAM, trimedoxime, obidoxime, and HI-6), are in clinical use. $^{13,17,18}$ Pralidoxime and obidoxime are the two currently clinically used drugs, and trimedoxime (TMB-4) and HI-6 have been tested in humans and are available for human use in some countries. $^{12}$

Received: August 19, 2017

Published: November 2, 2017 

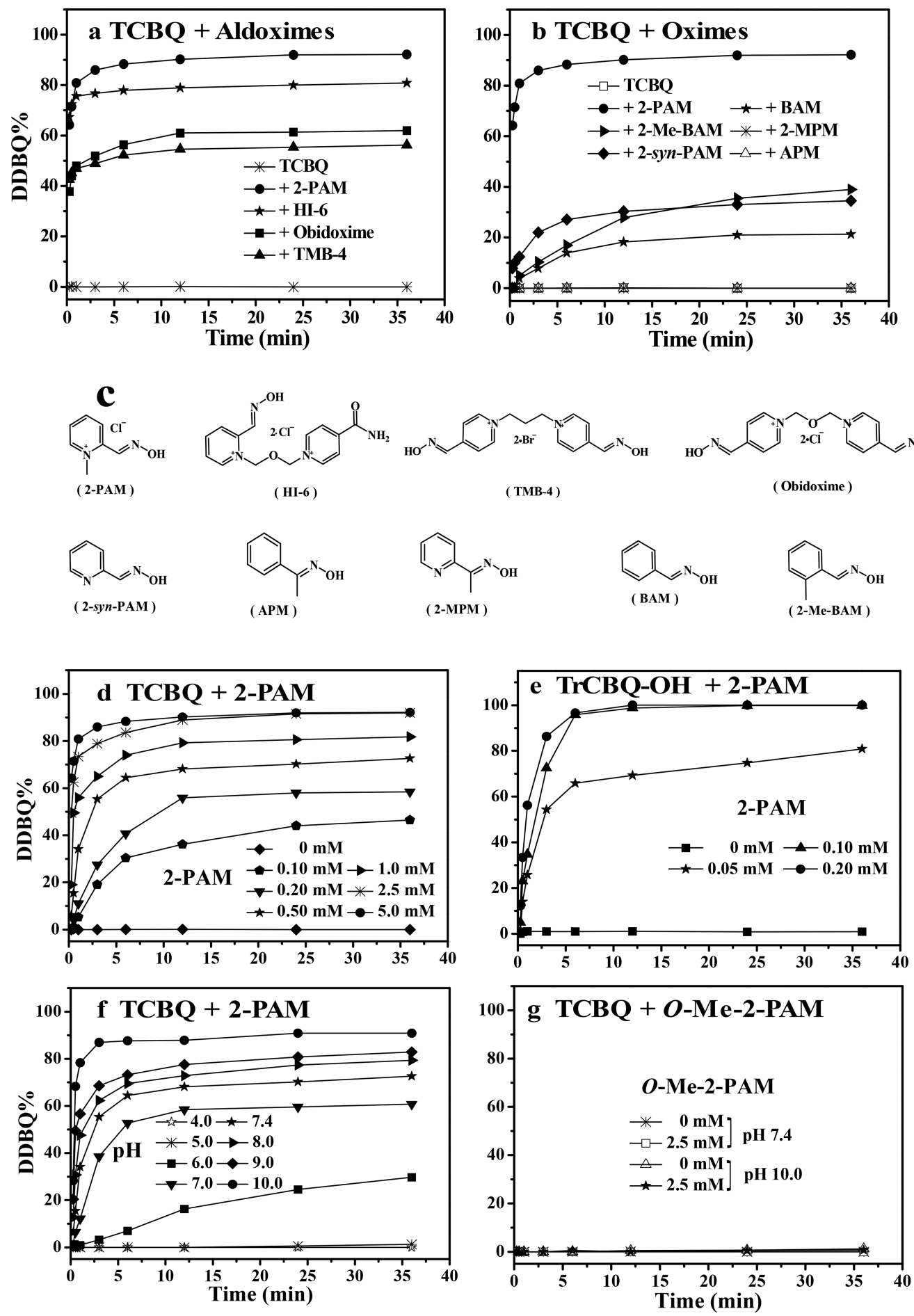

Figure 1. Dechlorination and dihydroxylation of TCBQ to DDBQ was dramatically accelerated by 2-PAM, other pyridinium aldoximes and oximes (a, b). 2-PAM: pralidoxime; TMB-4: trimedoxime bromide; obdioxime: obdioxime chloride; HI-6: asoxime chloride; 2-syn-PAM: syn-2pyridinealdoxime; APM: acetophenone oxime; 2-MPM: methyl 2-pyridyl ketoxime; BAM: benzaldehydeoxime; 2-Me-BAM: 2-methylbenzaldehydeoxime. TCBQ $0.05 \mathrm{mM}$; oximes, $5.0 \mathrm{mM}$. Chemical structures of the aldoximes and oximes used in this study (c). 2-PAM, but not $O$-methyl-2-PAM, enhanced the dechlorination and hydroxylation of TCBQ and TrCBQ-OH to DDBQ (d-g). 2-PAM enhanced hydrolysis of TCBQ (d) and TrCBQ-OH (e) in a concentration-dependent manner. (f) 2-PAM accelerated hydrolysis of TCBQ in a pH-dependent manner; TCBQ, $0.05 \mathrm{mM}$; 2-PAM, $0.50 \mathrm{mM}$. (g) O-Methyl-2-PAM did not accelerate hydrolysis of TCBQ even when the $\mathrm{pH}$ value reached 10. (d-g) The concentration of 2-PAM is indicated, TCBQ, $0.05 \mathrm{mM}$; TrCBQ-OH, $0.05 \mathrm{mM}$. The experiments were conducted in Chelex-treated phosphate buffer $(100 \mathrm{mM}, \mathrm{pH} 7.4)$ at $25{ }^{\circ} \mathrm{C}$. DDBQ formation was quantified for $36 \mathrm{~min}$ by HPLC analysis.

During our recent studies on the molecular mechanism of the protection of pyridinium aldoximes against the toxicity of organophosphorus and haloquinoid pesticides, we unexpectedly found that pyridinium aldoximes can efficiently detoxify TCBQ and other polyhalogenated quinoid compounds, the carcinogenic metabolites of PCP, and other persistent organic pollutants. Nevertheless, the detoxification mechanism remains not clear. We extensively examined the molecular mechanism 

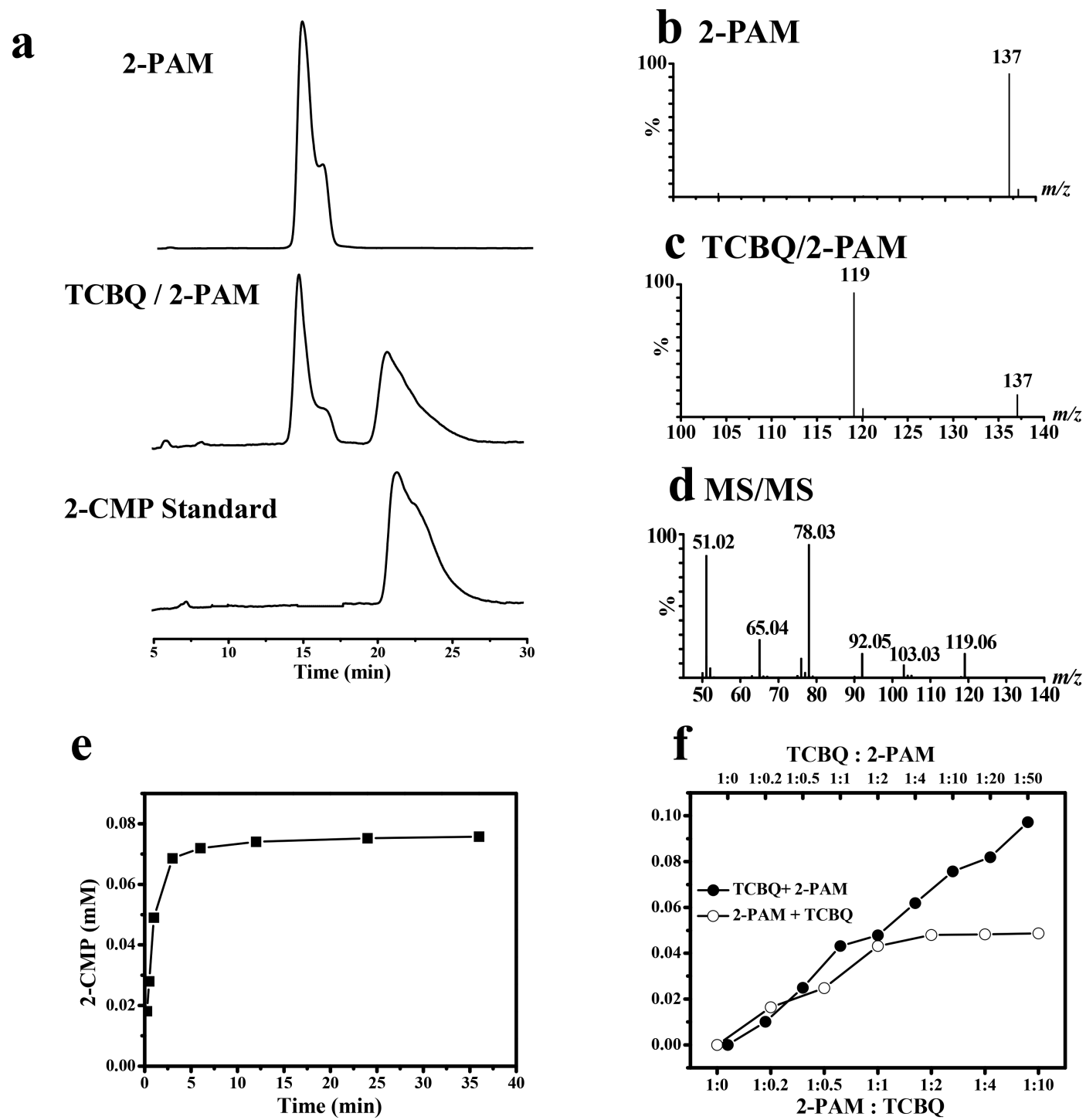

Figure 2. 2-Cyano-1-methylpyridinium chloride (2-CMP) was identified as the major product of 2-PAM after reacting with TCBQ by HPLC/MS: (a) Chromatogram of 2-PAM, TCBQ/2-PAM (TCBQ: 2-PAM = 1:2, TCBQ: $0.05 \mathrm{mM}, 36 \mathrm{~min}$ ), and 2-CMP (authentic standard). The MS spectra of 2-PAM (b) and TCBQ/2-PAM (c) (2-PAM: TCBQ = 1:10, 2-PAM: $0.05 \mathrm{mM}, 40 \mathrm{~s}$ ), MS/MS spectrum of 2-CMP (d). The synthetic 2-CMP has the same retention time (a), molecular ion peak and fragment ion peak (d) as the final major reaction product from 2-PAM. The reactions of (a), (b), (c), and (d) were conducted in Chelex-treated $\mathrm{CH}_{3} \mathrm{COONH}_{4}$ buffer $(\mathrm{pH} 7.4,100 \mathrm{mM})$ at $25{ }^{\circ} \mathrm{C}$. The time and dose-dependent formation of 2CMP from the reaction between 2-PAM and TCBQ (e, f): (e) TCBQ, $0.05 \mathrm{mM}$; 2-PAM, $0.5 \mathrm{mM}$. (f) 2-PAM, $0.05 \mathrm{mM}, 36 \mathrm{~min}$ (2-PAM + TCBQ); TCBQ, $0.05 \mathrm{mM}, 36 \mathrm{~min}(\mathrm{TCBQ}+2-\mathrm{PAM})$. The reactions of (e) and (f) were conducted in Chelex-treated phosphate buffer $(100 \mathrm{mM}, \mathrm{pH} 7.4)$ at $25{ }^{\circ} \mathrm{C}$.

of TCBQ and pyridinium aldoximes recently, using HPLC, HPLC/MS, NMR, and oxygen-18 isotope-labeling methods. Unexpectedly, this effective detoxication was found to be an unusually mild and facile Beckmann-type double fragmentation reaction.

\section{RESULTS AND DISCUSSION}

Pyridinium Aldoximes Accelerate the Hydrolysis of TCBQ Dramatically, and 2-Pyridinium Aldoxime Was the Most Effective One. TCBQ was first hydrolyzed to trichlorohydroxy-1,4-benzoquinone ( $\mathrm{TrCBQ}-\mathrm{OH})$, and then very slowly hydrolyzed to the final 2,5-dichloro-3,6-dihydroxy1,4-benzoquinone (chloranilic acid, or DDBQ) at neutral $\mathrm{pH}^{19}$ In this study, the four pyridinium aldoximes can markedly accelerate this hydrolysis process to DDBQ. Interestingly, we found that the two 2-pyridinium aldoximes (2-PAM and HI-6) are more effective than the two 4-pyridinium aldoximes (obidoxime and TMB-4) (Figure 1a), and among the four studied pyridinium aldoximes antidotes, 2-PAM was determined to be the most effective one. Next, we compared 2-PAM with five other oximes that have very similar structures, including syn-2-pyridinealdoxime (2-syn-PAM), benzaldehydeoxime (BAM), 2-methyl-benzaldehydeoxime (2-Me-BAM), acetophenone oxime (APM), and methyl 2-pyridyl ketoxime (2-MPM), and 2-PAM was also determined to be the most effective at accelerating this hydrolysis process. Interestingly, 2PAM was much more efficient than 2-syn-PAM, indicating that the methylation of the nitrogen in pyridine may increase the nucleophilicity of aldoximes (i.e., the $\mathrm{p} K_{\mathrm{a}}$ values of 2-PAM and 2 -syn-PAM are 7.68 and 8.41, respectively) ${ }^{14,20}$ (Figure 1b).

On the basis of these results and that 2-PAM, which is the first and most clinically used aldoxime since 1955, possesses the 
simplest chemical structure among the four pyridinium aldoxime antidotes, 2-PAM was chosen as a model pyridinium aldoxime for further mechanistic investigations.

In our previous research, we observed that TCBQ can be hydrolyzed to the initial transient intermediate $\operatorname{TrCBQ}-\mathrm{OH}$ and final product $\mathrm{DDBQ} .^{21-24}$ The TCBQ/2-PAM system was determined by electrospray ionization quadrupole time-of-flight mass spectrometry (ESI-Q-TOF-MS), and the same results were observed. The generation of $\operatorname{TrCBQ}-\mathrm{OH}$ and DDBQ was dependent on the molar ratios of 2-PAM/TCBQ. When the molar ratios are $\leq 1$, TCBQ was primarily converted to TrCBQ-OH. In the presence of excess 2-PAM (the molar ratios $>1$ ), TCBQ was initially converted to $\mathrm{TrCBQ}-\mathrm{OH}$, and then to the final product DDBQ (for details, see Figure S1a,c-f of the Supporting Information, SI). To determine whether TrCBQ-OH can be directly converted into DDBQ by 2-PAM, TrCBQ-OH was synthesized as previously described, and this transformation was confirmed (see Figure S1b,g).

The hydrolysis rate also depends on the molar ratios of 2$\mathrm{PAM} / \mathrm{TCBQ}$ and 2-PAM/TrCBQ-OH (Figure 1d,e). The rate increased as the molar ratio increased. For instance, the half time of TCBQ $(0.05 \mathrm{mM})$ to DDBQ was observed to be $10,2.39,0.5,0.25$, and less than $0.17 \mathrm{~min}$, respectively $(\mathrm{pH}$ 7.4 ), in the presence of $0.2,0.5,1.0,2.5$, and $5.0 \mathrm{mM}$ 2-PAM. As the half-time is 21-days for TCBQ hydrolysis to DDBQ ${ }^{19}$ our data suggest that 2-PAM can enhance TCBQ hydrolysis to DDBQ up to 180000 -fold (TCBQ $0.05 \mathrm{mM}$; 2-PAM, 5.0 $\mathrm{mM})$.

It is important to note that the ratios of DDBQ were not $100 \%$, even at a high 2-PAM concentration and $\mathrm{pH}$, which may due to a side reaction between TCBQ (or TrCBQ-OH) and 2-PAM. This process will require additional study in the future.

When TCBQ was replaced by other tetrahalogenated quinones, including tetrabromo- and tetrafluo-1,4-benzoquinones (TBrBQ TFBQ) and tetrachloro-1,2-hydroquinone (TCHQ), as well as tetrachloro-1,2-benzoquinone ( $O$ TCBQ), similar accelerated hydrolysis effects were observed (see Figures S2-S5). As previously mentioned (Figure 1a,b), when 2-PAM was replaced with other aldoximes, such as trimedoxime, obidoxime, HI-6, 2-syn-PAM, BAM, and 2-Me$\mathrm{BAM}$, analogous results were noticed. Our results demonstrate that this reaction is common among all aldoximes and tetrahalogenated quinoid compounds.

The Free Pralidoxime Anion Is Crucial for the Enhancement of TCBQ Conversion to DDBQ. The $\mathrm{pH}$ of the buffer is crucial for the rate of 2-PAM-mediated TCBQ conversion to DDBQ. Hydrolysis was not observed at a $\mathrm{pH}$ of $\leq 4$. However, as the $\mathrm{pH}$ increased, the rate of hydrolysis gradually increased (Figure 1f). On the basis of these results, we assume that the free pralidoxime anion may be the reactive form of 2-PAM $\left(\mathrm{p} K_{\mathrm{a}}=7.68\right)$. In this case, we expect that the TCBQ hydrolysis will not be accelerated when the free anionic oxygen is blocked. To further confirm this hypothesis, $O$ methyl-2-PAM $\left(\mathrm{Py}^{+}\left(\mathrm{CH}_{3}\right)-\mathrm{CH}=\mathrm{N}-\mathrm{O}-\mathrm{CH}_{3}\right)$ was synthesized. $^{25}$ As expected, O-methyl-2-PAM did not accelerate TCBQ hydrolysis, even when the $\mathrm{pH}$ value reached 10 (Figure $1 \mathrm{~g})$. These findings demonstrated that the free pralidoxime anion is required for substantial enhancement of TCBQ conversion to DDBQ.

The Major Reaction Product of 2-PAM Was Identified as Its Corresponding Nitrile (i.e., 2-Cyano-1-methylpyridinium Chloride). Since the rate of TCBQ hydrolysis with 2$\mathrm{PAM}$ is greatly accelerated compared with its spontaneous hydrolysis, this process may be catalyzed by 2-PAM. However, during the interaction with TCBQ, 2-PAM was consumed, and a new product with $\mathrm{m} / z$ at 119 was simultaneously generated (Figure $2 \mathrm{~b}, \mathrm{c}$ ). This result demonstrated that 2-PAM participate in the reaction rather than act as a catalyst.

To further explore the underlying molecular mechanism between 2-PAM and TCBQ, we isolated and purified the major product. $^{26,27}$ Interestingly, 2-cyano-1-methylpyridinium chloride (2-CMP, eq 1 ) was found to be the main reaction product of 2-PAM, with a yield of up to $97.4 \%$ (Figure 2a,d-f). Similar results were also observed for $\mathrm{TrCBQ}-\mathrm{OH} / 2-\mathrm{PAM}$ (see Figure S6).

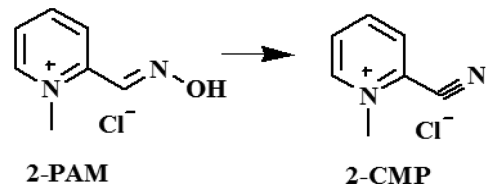

This raised a new question: what pathway would result in 2CMP being generated from 2-PAM? After consulting the literature, we determined that the classical Beckmann fragmentation was responsible for this reaction. Beckmann fragmentation is the reaction that involves the transformation of an oxime $\left(\mathrm{R}_{1}-\left(\mathrm{R}_{2}\right) \mathrm{C}=\mathrm{N}-\mathrm{OH}\right)$ into the corresponding nitrile $\left(\mathrm{R}_{1}-\mathrm{C} \equiv \mathrm{N}\right)$ via a nitrilium cation and/or carbocation intermediate. ${ }^{28-32}$ The conversion of the $N$-hydroxy group of the oxime into a better leaving group (via protonation, etherification, or esterification), is necessary to initiate this reaction. ${ }^{30,32}$ Therefore, the activation of the oxygen atom of oxime by an activating agent (usually by strong electrophiles such as diethyl chlorophosphate and chlorosulfonic acid) is very important for the Beckmann fragmentation to occur ( $A$ is the activator by losing a halogen or other active group, and $\mathrm{OA}$ is an acceptable leaving group, eq 2):

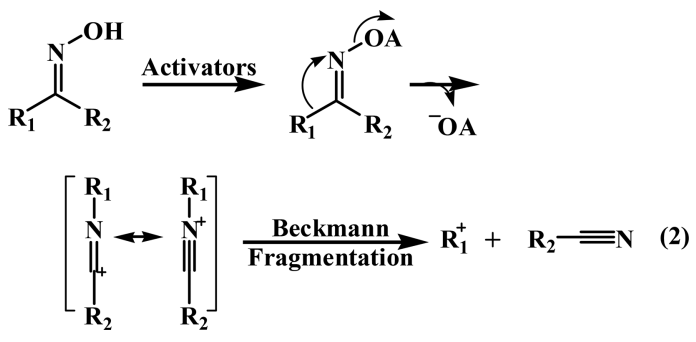

It is important to note that if TCBQ was replaced by other tetrahaloquinones, like TBrBQ, TFBQ, TCHQ and $O-T C B Q$, 2-CMP was also identified as the major reaction product of 2PAM, and the yield was determined to be $97.1 \%, 96.8 \%, 74.2 \%$, and $100 \%$, respectively (see Figure S7); when 2-PAM was replaced by other pyridinium aldoximes, the corresponding nitrile products were also identified by HPLC-ESI-MS when they reacted with TCBQ (see Figure S8). On the basis of these experimental results, an analogous, but previously unknown Beckmann-type fragmentation pathway may occur between pyridinium aldoximes and tetrahalogented quinoid compounds.

Molecular Mechanism of 2-PAM-Mediated Enhancement of TCBQ Hydrolysis: Nucleophilic Substitution Coupled with an Unprecedented Double Beckmann Fragmentation. On the basis of our results, and pralidoxime anion being an effective $\alpha$-nucleophile, we proposed a novel mechanism for 2-PAM-enhanced hydrolysis of TCBQ (Scheme 1): A nucleophilic attack of the pralidoxime anion $\left(\mathrm{Py}^{+}\left(\mathrm{CH}_{3}\right)-\right.$ 
Scheme 1. Proposed Molecular Mechanism of 2-PAM-

Mediated Enhancement of TCBQ Hydrolysis: Nucleophilic Attack Coupled with an Unusually Facile Double Beckmann Fragmentation under Physiological Conditions

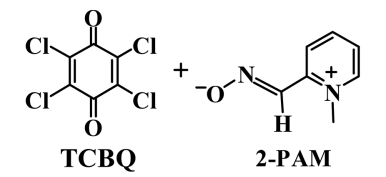

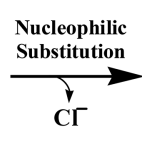<smiles>C[n+]1ccccc1C=NC=O</smiles>

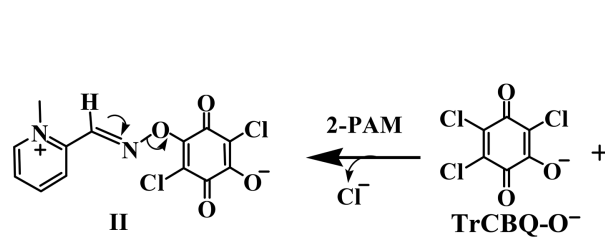

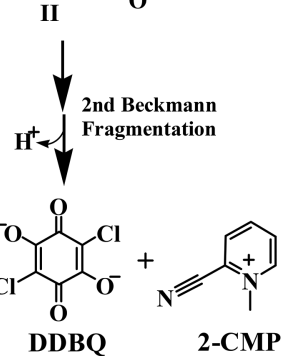

1st Beckmann $\checkmark$ Fragmentation
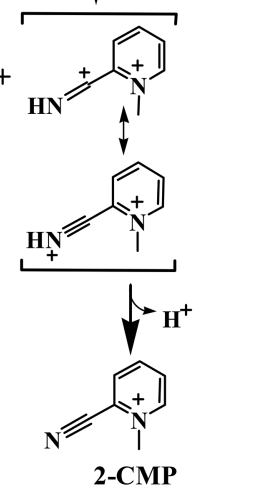

$\mathrm{CH}=\mathrm{N}-\mathrm{O}^{-}$) on $\mathrm{TCBQ}$ forms an unstable transient intermediate $\mathrm{Py}^{+}\left(\mathrm{CH}_{3}\right)-\mathrm{CH}=\mathrm{N}-\mathrm{O}$-trichloro-1,4-benzoquinone, which undergoes a Beckmann-type fragmentation. This fragmentation leads to the formation of the monohydroxylation intermediate $\mathrm{TrCBQ}_{-} \mathrm{O}^{-}$and the cationic nitrilium ion $\mathrm{Py}^{+}\left(\mathrm{CH}_{3}\right)-\mathrm{C} \equiv \mathrm{NH}^{+}$, which is in equilibrium with carbocation $\mathrm{Py}^{+}\left(\mathrm{CH}_{3}\right)-\mathrm{C}^{+}=\mathrm{NH}$. Then, a proton loss results in the formation of the nitrile 2-CMP. In the presence of excess 2$\mathrm{PAM}, \mathrm{TrCBQ}-\mathrm{O}^{-}$may further react with 2-PAM to form analogous reaction intermediates, which can further convert to dihydroxylation final product DDBQ and another molecule of 2-CMP via a second-step Beckmann-type fragmentation reaction.

If this proposed double Beckmann-type fragmentation mechanism is correct, the source and origin of the oxygen atom in TrCBQ-OH and DDBQ can be traced from the hydroxyl group of 2-PAM not from the reaction buffer. ${ }^{24}$ To further confirm the proposed mechanism, TCBQ (or TrCBQ$\mathrm{OH}$ ) was reacted with 2-PAM in $\mathrm{CH}_{3} \mathrm{COONH}_{4}$ buffer using oxygen-18-labeled $\mathrm{H}_{2} \mathrm{O}\left(\left[{ }^{18} \mathrm{O}\right]-\mathrm{H}_{2} \mathrm{O}\right)$ as the solvent. If $\mathrm{H}_{2} \mathrm{O}$ is the source and origin of the oxygen atom in either TrCBQ$\mathrm{OH}$ and $\mathrm{DDBQ}$, then the mass spectra of $\mathrm{TrCBQ}-\mathrm{OH}$ and DDBQ should demonstrate the shift of 2 and 4 mass units compared to the unlabeled compounds. However, the mass

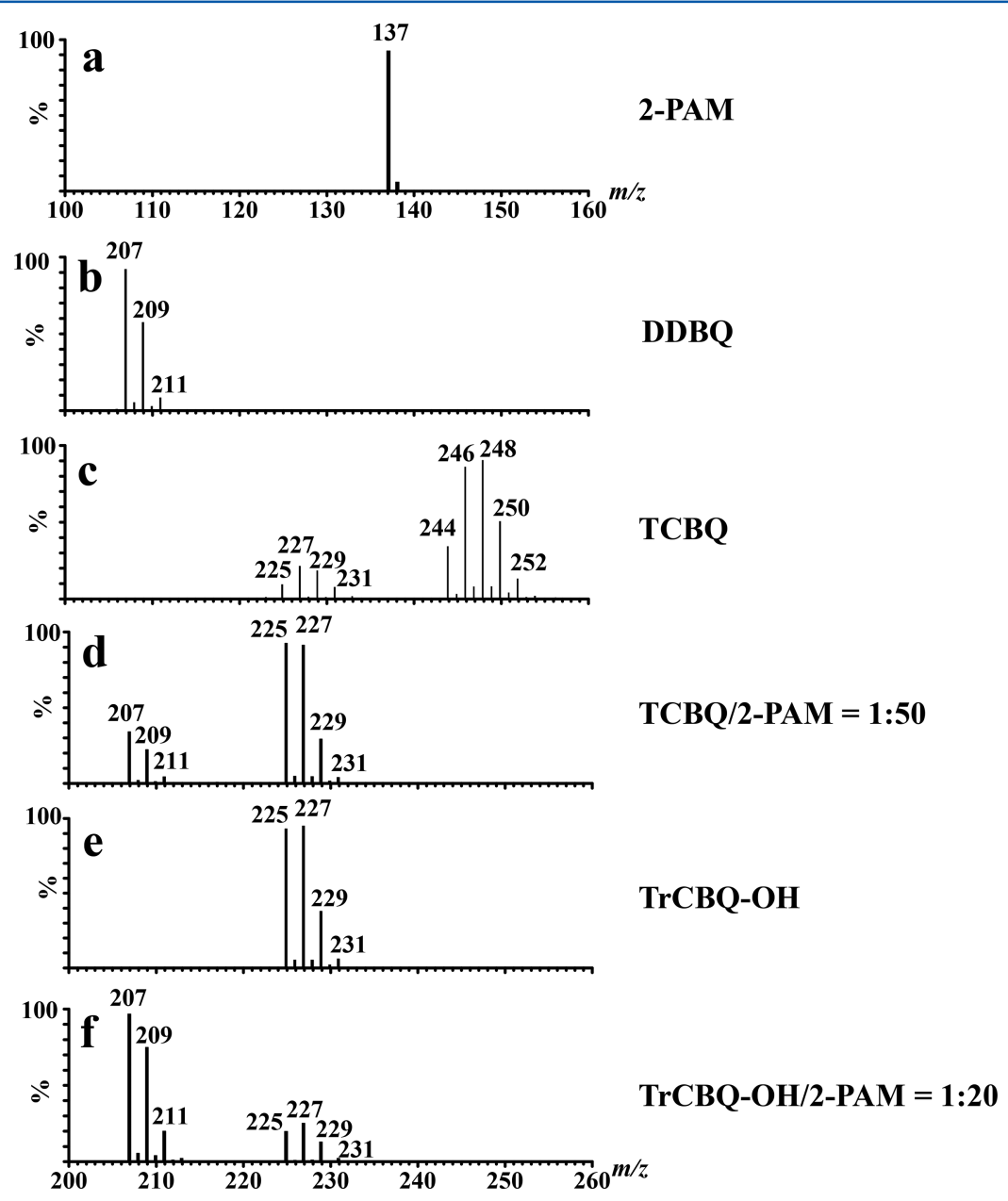

Figure 3. Mass spectral analysis of the dechlorination and hydroxylation products for TCBQ in buffer solution prepared with oxygen-18-labeled $\mathrm{H}_{2} \mathrm{O}$. The MS spectra of 2-PAM (a), DDBQ (b), TCBQ (c), TCBQ:2-PAM = 1:50 (d), TrCBQ-OH (e), and TrCBQ-OH:2-PAM = 1:20 (f) in Chelex-treated $\mathrm{CH}_{3} \mathrm{COONH}_{4}(\mathrm{pH} 7.4,100 \mathrm{mM})$ using oxygen-18-labeled $\mathrm{H}_{2} \mathrm{O}\left(\left[{ }^{18} \mathrm{O}\right]-\mathrm{H}_{2} \mathrm{O}, 97 \%\right)$ as solution. TCBQ $0.1 \mathrm{mM}$; TrCBQ-OH, 0.1 $\mathrm{mM}$; 2-PAM, $2 \mathrm{mM}$, or $5 \mathrm{mM}, 25^{\circ} \mathrm{C}$. 
$\mathbf{a}$

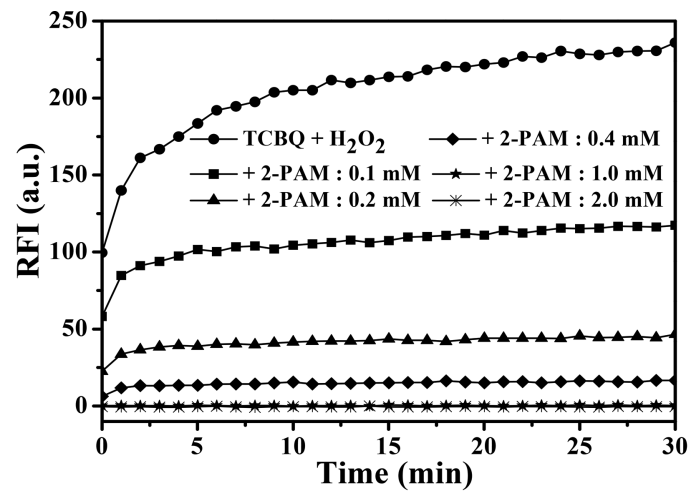

b

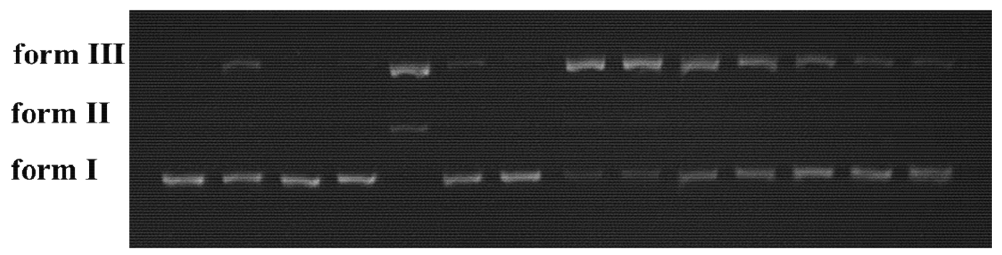

\begin{tabular}{|c|c|c|c|c|c|c|c|c|c|c|c|c|c|}
\hline TCBQ & + & & & + & + & & + & + & + & + & + & + & + \\
\hline $\mathrm{H}_{2} \mathrm{O}_{2}$ & & & + & + & & + & + & + & + & + & + & + & + \\
\hline 2-PAM & & + & & & + & + & 0.1 & 0.2 & 0.4 & 1.0 & 2.0 & 5.0 & 10.0 \\
\hline
\end{tabular}

Figure 4. (a) Inhibition by 2-PAM of hydroxyl radicals produced by TCBQ/ $\mathrm{H}_{2} \mathrm{O}_{2}$ as measured by fluorescent method using TPA as a probe. TCBQ: $0.1 \mathrm{mM}, \mathrm{H}_{2} \mathrm{O}_{2}: 1 \mathrm{mM}$; TPA: $20 \mathrm{mM}$. (b) Protection by 2-PAM against TCBQ $/ \mathrm{H}_{2} \mathrm{O}_{2}$-induced DNA double-strand breaks. The plasmid pBR322 DNA $(5 \mu \mathrm{g} / \mathrm{mL})$ was incubated at $37{ }^{\circ} \mathrm{C}$ for $1 \mathrm{~h}$ in Chelex-treated phosphate buffer $\left(0.1 \mathrm{M}, \mathrm{pH}\right.$ 7.4), TCBQ: $0.1 \mathrm{mM}, \mathrm{H}_{2} \mathrm{O}_{2}: 1 \mathrm{mM}$.

spectra of TrCBQ-OH or DDBQ did not shift (Figure 3). The isotope-labeling results provided more convincing experimental evidence and further confirmed the proposed Beckmann-type fragmentation mechanism (Scheme 1).

Why this Beckmann Fragmentation Reaction Is Unique? The activation of the oxygen atom of aldoximes is crucial for Beckmann fragmentation. In previous studies, the Beckmann fragmentation is typically achieved by using $O$ activated aldoxime derivatives (i.e., aldoxime ethers or esters). Other activation methods of free aldoximes often employ various activating agents, such as concentrated $\mathrm{H}_{2} \mathrm{SO}_{4}$, diethyl chlorophosphate, chlorosulfonic acid, either via protonation, etherification, or esterification (see Table S1). ${ }^{32,33}$ To the best of our knowledge, this study is the first report of the use of TCBQ and other tetrahalogenated quinones as the special activation agents for free aldoximes, affording unstable $O$ trihaloquinonated aldoximes that spontaneously undergo two consecutive Beckmann-type fragmentations.

Numerous studies have demonstrated that Beckmann-type fragmentation reactions occur in only one step under strong acidic conditions by heating to a required temperature in organic solvents. ${ }^{30,32}$ In the current study, the reaction between 2-PAM and TCBQ occurred via a two-step or double Beckmann fragmentation reaction, which took place at room temperature and under neutral or even alkaline $\mathrm{pH}$ in aqueous buffer solutions (i.e., under normal physiological conditions). This reaction may be due to the unusually rapid and facile fragmentation of the proposed reaction intermediate (i.e., $\mathrm{O}$ trichloroquinonated 2-PAM or $\mathrm{O}$-trichloroquinonated aldoxime ether). A recent study reported that the stability of haloquinone-activated benzohydroxamate intermediates was well correlated with the $\mathrm{pK}_{\mathrm{a}}$ value of the corresponding conjugate acids. ${ }^{34} \mathrm{We}$ speculated that this correlation may also apply to $\mathrm{O}$-trichloroquinonated aldoxime ethers. Both
$\operatorname{TrCBQ}-\mathrm{OH}\left(\mathrm{p} K_{\mathrm{a}}: 1.10\right)$ and DDBQ $\left(\mathrm{p} K_{\mathrm{a} 1}: 0.58 ; \mathrm{p} K_{\mathrm{a} 2}\right.$ : 2.72) possess strong acidity, and are the conjugate acids of the anionic leaving groups in the proposed mechanism (Scheme 1). Therefore, the fragmentation rate of the proposed reaction intermediates should be very fast. Once formed, these intermediates should fragment extremely rapidly under physiological conditions, which may result in 2-PAM and other aldoximes substantially enhancing the hydrolysis of TCBQ (or TrCBQ-OH) to DDBQ at room temperature and under neutral $\mathrm{pH}$. This explanation may also be the reason why the proposed reaction intermediates cannot be isolated and identified in the current study, unlike other $O$-substituted oximes.

Pyridinium Aldoximes Provide Marked Protection against TCBQ-Mediated DNA Damage. In our previous studies, TCBQ produced highly reactive hydroxyl radicals $(\bullet \mathrm{OH})$ in the presence of $\mathrm{H}_{2} \mathrm{O}_{2}$ through a metal-independent mechanism, which can lead to DNA strand breakage ${ }^{3,21}$ and base oxidations. ${ }^{35,36}$ The transformation of covalently closed circular double-stranded supercoiled DNA (form I) to relaxed open circle (form II) and linear forms (form III) has been widely employed to investigate DNA strand breakage using a gel electrophoresis method. ${ }^{37}$ We determined that 2-PAM can provide strong protection against TCBQ $/ \mathrm{H}_{2} \mathrm{O}_{2}$-induced DNA double-strand breaks in isolated DNA (Figure 4b). The protection by 2-PAM was due to its efficient inhibition of - $\mathrm{OH}$ formation by TCBQ $/ \mathrm{H}_{2} \mathrm{O}_{2}$, and was measured using fluorescent methods and terephthalic acid as a trapping agents (Figure 4a).

Pyridinium Aldoximes Provide Marked Protection against TCBQ-Induced Cytotoxicity in Two Model CellCulture Systems. Then the study was extended from isolated DNA to bacterial and mammalian cells using P. phosphoreum and human hepatoma (HepG2) as two model cell culture 

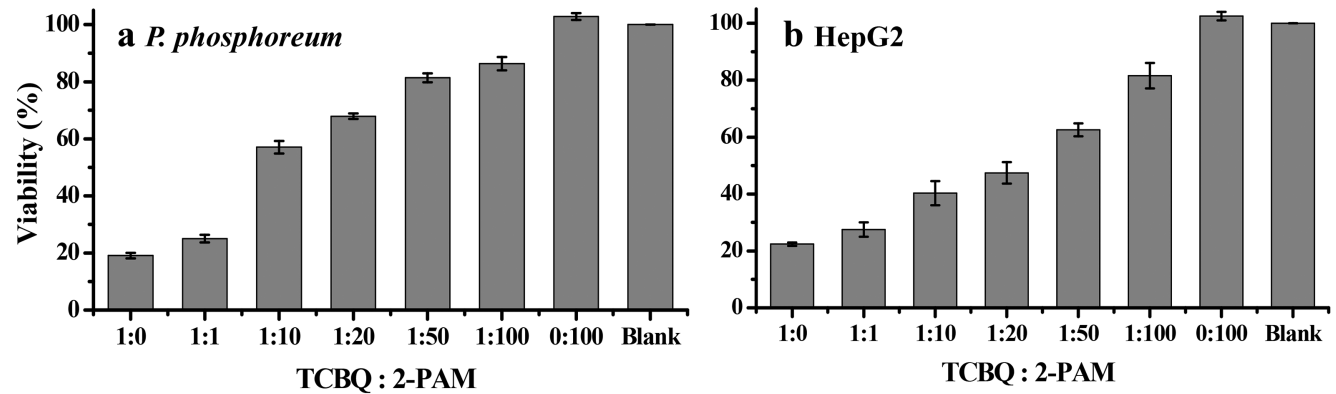

c

\begin{tabular}{|c|c|c|c|c|c|}
\hline & TCBQ & TrCBQ-OH & DDBQ & 2 -PAM & 2 -CMP \\
\hline P. phosphoreum & 2.6 & 19.5 & 676.9 & $6.3 \times 10^{4}$ & $1.6 \times 10^{4}$ \\
\hline HepG2 Cell & 2.0 & 94.0 & 613.9 & $1.4 \times 10^{5}$ & $5.3 \times 10^{4}$ \\
\hline
\end{tabular}

Figure 5. Protection by 2-PAM against TCBQ-induced toxicity in P. phosphoreum and HepG2 cells. (a) The P. phosphoreum experiment was performed at $20{ }^{\circ} \mathrm{C}$ for $15 \mathrm{~min}$ in Chelex-treated sodium phosphate buffer (100 mM, pH 7.4, 3\% NaCl); TCBQ: $0.01 \mathrm{mM}$. (b) The HepG2 experiment was conducted via incubation of cells in RPMI 1640 mediumat $37{ }^{\circ} \mathrm{C}$ for $2 \mathrm{~h}$; TCBQ: $0.008 \mathrm{mM}$. (c) The IC 50 values of TCBQ TrCBQ-OH, DDBQ 2-CMP, and 2-PAM in P. phosphoreum and HepG2 cells. Each point was repeated twice, and the SD was less than 5\%.

systems. The P. phosphoreum toxicity assay, which is commonly known as the Microtox assay, ${ }^{38}$ is a conventional method for evaluating chemicals' potential acute aquatic toxicity, especially environmental samples and products generated from waste treatment or remediation processes. The luminescence of $P$. phosphoreum is directly related to respiratory activity, and the intensity of the luminescence is a good indicator for the metabolic activity. Therefore, the compound's general cytotoxicity can be determined. ${ }^{19}$

Using this model system, the protection of 2-PAM for TCBQ-induced toxicity was remarkable and dose-independent. A 2-PAM concentration of $1.0 \mathrm{mM}$ protected against TCBQinduced toxicity by $67.2 \%$ (Figure $5 \mathrm{a}$ ). The $\mathrm{IC}_{50}$ values of TCBQ TrCBQ-OH, DDBQ 2-PAM, and 2-CMP were measured by $P$. phosphoreum (Figure $5 \mathrm{c}$ ). On the basis of these results, DDBQ is much less toxic than TCBQ and TrCBQ-OH (The $\mathrm{IC}_{50}$ values for DDBQ TCBQ and TrCBQ-OH were $676.9 \mu \mathrm{M}, 2.6 \mu \mathrm{M}$, and $19.5 \mu \mathrm{M}$, respectively).

Since halogenated quinones and their parent phenols have been shown to cause hepatoxicity, ${ }^{1,2,35}$ HepG2 cells were chosen as a model human liver cell culture model for further study. The experiment was conducted by pretreating the cells with 2-PAM followed by treatment with TCBQ, and the cell survival was measured using a MTT assay. ${ }^{39}$ Analogous protective effects were observed with the HepG2 cells (Figure $5 b)$. The $\mathrm{IC}_{50}$ values for TCBQ TrCBQ-OH, and DDBQ were determined to be $2.0 \mu \mathrm{M}, 94.0 \mu \mathrm{M}$, and $613.9 \mu \mathrm{M}$, respectively (Figure 5c). Interestingly, the $\mathrm{IC}_{50}$ values for DDBQ were much higher than those of TCBQ in both $P$. phosphoreum and HepG2 cells, which suggests that the conversion of TCBQ to DDBQ by 2-PAM is an efficient detoxification process in the two model cell culture systems. Similar protective effects were also observed for other pyridinium aldoximes (i.e., HI-6, TMB-4, and obidoxime) (see Figure S9).

Pyridinium aldoximes have been widely employed as antidotes to treat organophosphorus-based agents intoxications for more than 60 years. On the basis of these experimental results, we propose that pyridinium aldoximes may also be employed as potential antidotes for detoxifying carcinogenic polyhalogenated quinones in the future.

\section{CONCLUSIONS}

On the basis of our results, we can see that this unusual Beckmann-type fragmentation reaction mechanism is a universal mechanism for all haloquinoid and pyridinium aldoxime compounds, not limited to TCBQ and 2-PAM. Therefore, this research represents broad environmental and biomedical significance, because a great deal of widely used polyhalogenated aromatic compounds can be dehalogenated to form the corresponding quinones. ${ }^{1-3,5-7,40-43}$ Polychloroquinones have also been detected in discharges from paper and pulp industries, ${ }^{22}$ and more importantly, 12 haloquinones have been newly identified as a class of carcinogenic disinfection byproducts, which are potential bladder carcinogens. ${ }^{8}$ These halogenated quinones could induce stronger cytotoxicity and/ or stronger developmental toxicity than most of the other regulated disinfection byproducts. ${ }^{10}$ Cellular mechanistic studies have demonstrated that haloquinones can produce reactive oxygen species (ROS), deplete cellular glutathione levels, and influence cellular antioxidant enzymes, which can induce oxidative stress and oxidatively damage cellular DNA, proteins, and lipids. ${ }^{1,3,10,21}$ ROS generation along with activation of MAPK signaling could represent essential mechanisms that explain how PCP triggers tumor promotion. ${ }^{44}$ Our recent studies have also demonstrated that polyhaloquinones along with $\mathrm{H}_{2} \mathrm{O}_{2}$ and/or organic hydroperoxides can effectively cause various DNA damages, oxidize $5 \mathrm{mdC}$ to form methyl oxidation products, ${ }^{35,45}$ and induce lipid peroxidation. ${ }^{46}$ Therefore, these polyhaloquinones are potential carcinogens, and it is critically important to detoxify them under mild conditions.

In fact, four pyridinium aldoximes (pralidoxime, trimedoxime, obidoxime, and HI-6) have been employed into clinical treating the poisonings by organophosphorus pesticides or nerve-agents. ${ }^{12,13}$ The good activity of pyridinium aldoximes is because of the strong binding of the positively charged pyridinium to the enzyme active site as well as the proper 
orientation of oxime group for replacement of the phosphyl moiety. As demonstrated in the current study, these compounds are also effective for detoxification of polyhaloquinones, which are a class of carcinogenic intermediates and recently identified disinfection byproducts. Interestingly, pyridinium aldoximes react directly with organophosphorus chemical warfare agents, or activate the inhibited enzyme by forming phosphyloximes, which decompose to produce phosphilic acid and the corresponding nitriles in vitro, ${ }^{12,16}$ via a potentially analogous Beckmann-type fragmentation reactions. In addition, pyridinium aldoximes are beneficial in carbamate pesticides poisoning and can inhibit the cholinergic activity. The detoxification courses are similar to poisoning by organophosphorus agents. ${ }^{47,48}$ Therefore, this unusual Beckmann-type fragmentation may be a universal, but previously unrecognized new detoxification molecular mechanism for the currently clinically used pyridinium aldoxime therapeutic agents. Our results represent broad environmental and biomedical significance for future investigation of polyhalogenated aromatic pollutants and pyridinium aldoximes, which are two important classes of compounds that have attracted the attention of both the general public and academic researchers. Additional study is required to determine whether pyridinium aldoximes can be effectively and safely used to prevent or treat various human diseases, for example, bladder or liver cancer related to haloquinones.

\section{EXPERIMENTAL SECTION}

Chemicals. Tetrachloro-1,4-benzoquinone (TCBQ) was purchased from Fluka. Pyridine-2-aldoxime methochloride (2-PAM), chloranilic acid, and trimedoxime bromide (TMB-4) were purchased from Sigma-Aldrich. Asoxime chloride (HI-6) and obidoxime chloride were purchased from Toronto Research Chemicals. The oxygen-18enriched $\mathrm{H}_{2} \mathrm{O}\left(97 \%,\left[{ }^{18} \mathrm{O}\right]-\mathrm{H}_{2} \mathrm{O}\right)$ was purchased from Aladdin. Trichlorohydroxy-1,4-benzoquinone (TrCBQ-OH), 2-cyano-1-methylpyridinium iodine (2-CMP), and $O$-methyl-2-PAM were synthesized according to the previously published methods. ${ }^{21,25,26}$

Quantification of DDBQ and 2-CMP. DDBQ. DDBQ was measured according to the previously published method. ${ }^{19}$

2-CMP. The quantification of 2-CMP employed the same equipment and reaction buffer as DDBQ. However, the reaction was monitored at $269 \mathrm{~nm}$ using a $3.9 \times 300 \mathrm{~mm} \mathrm{10}-\mu \mathrm{m} \mu$ Porasil column (Waters Associates). ${ }^{27}$ The mobile phase consisted of water:acetonitrile (10:90), in which the aqueous component contained $8.36 \mathrm{mM}$ tetraethylammonium chloride dissolved in 3/1000 aqueous acetic acid solution, and the $\mathrm{pH}$ was 2.9 . The flow rate was $1.0 \mathrm{~mL} /$ min.

Fluorescent Method for Hydroxyl Radical Detection. Terephthalic acid (TPA, nonfluorescent) provides a single product, 2-hydroxyl-TPA (fluorescent) in reactions with hydroxyl radicals. First, $200 \mathrm{mM}$ TPA was dissolved in a $500 \mathrm{mM} \mathrm{NaOH}$ solution. Next, TPA was added to phosphate buffer $(100 \mathrm{mM}, \mathrm{pH} 7.4)$. Then, 2-PAM, TCBQ and $\mathrm{H}_{2} \mathrm{O}_{2}$ were added to the buffer in the following order: TCBQ $0.1 \mathrm{mM}, \mathrm{H}_{2} \mathrm{O}_{2}, 20 \mathrm{mM}, \mathrm{TPA}, 20 \mathrm{mM}$. The fluorescence intensity of the reaction mixture $(1 \mathrm{~mL})$ was measured by excitation at $310 \mathrm{~nm}$ and emission at $425 \mathrm{~nm}$.

The Photobacterium phosphoreum Toxicity Assay. P. phosphoreum were grown in the dark at $18{ }^{\circ} \mathrm{C}$ in liquid medium, and the cultures were harvested when an absorbance of 0.6 at $600 \mathrm{~nm}$ was reached. The liquid medium was composed of $1 \mathrm{~g} / \mathrm{L} \mathrm{KH}_{2} \mathrm{PO}_{4}, 5$ $\mathrm{g} / \mathrm{L} \mathrm{Na} \mathrm{HPO}_{4}, 30 \mathrm{~g} / \mathrm{L} \mathrm{NaCl}, 3 \mathrm{~mL} / \mathrm{L}$ glycerol, $5 \mathrm{~g} / \mathrm{L}$ yeast extract, and $5 \mathrm{~g} / \mathrm{L}$ tryptone and adjusted to a $\mathrm{pH}$ of 6.5 . When the P. phosphoreum reached logarithmic phase, it was diluted in Chelex-treated sodium phosphate buffer and $3 \% \mathrm{NaCl}(0.1 \mathrm{M}, \mathrm{pH} 7.4)$ in a $2: 50$ ratio. The experiment was conducted at $18{ }^{\circ} \mathrm{C}$ in a $200 \mu \mathrm{L} P$. phosphoreum solution by treating 2-PAM with TCBQ for $15 \mathrm{~min}$ (TCBQ: 0.01
$\mathrm{mM}$ ). Then, the luminescence intensity was measured at $475 \mathrm{~nm}$ using a Thermo Scientific Varioskan Flash.

2-Cyano- $N$-methylpyridinium lodine (2-CMP). The ${ }^{1} \mathrm{H}$ NMR and ${ }^{13} \mathrm{C}$ NMR spectra were recorded on a Bruker ARX 400 spectrometer using $\mathrm{D}_{2} \mathrm{O}$ as solvent. ${ }^{1} \mathrm{H}$ NMR $\delta=4.72(\mathrm{~s}, 3 \mathrm{H}), 8.49(\mathrm{t}, 1 \mathrm{H}), 8.75(\mathrm{~d}$, $1 \mathrm{H}), 8.87(\mathrm{t}, 1 \mathrm{H}), 9.28(\mathrm{~d}, 1 \mathrm{H}) ;{ }^{13} \mathrm{C}$ NMR $\delta=48.9\left(\mathrm{CH}_{3}\right), 127.5$ $(\mathrm{CN}), 110.6,132.0,134.3,146.8,149.5$ (PyC). The synthetic 2-CMP has the same retention time, molecular ion peak, and MS/MS fragment as the product of TCBQ/2-PAM (TCBQ, $0.2 \mathrm{mM}$; 2-PAM, $0.1 \mathrm{mM}$; pH 7.4, $25^{\circ} \mathrm{C}$ ) (Figure $\mathrm{S} 10$ ).

O-Methyl Pralidoxime (O-Methyl-2-PAM). The ${ }^{1} \mathrm{H}$ NMR and ${ }^{13} \mathrm{C}$ NMR spectra were recorded on a Bruker ARX 400 spectrometer using $\mathrm{D}_{2} \mathrm{O}$ as the solvent. ${ }^{1} \mathrm{H}$ NMR $\delta=4.24(\mathrm{~s}, 3 \mathrm{H}), 4.48(\mathrm{~s}, 3 \mathrm{H}), 8.09(\mathrm{t}$, $1 \mathrm{H}), 8.50(\mathrm{~d}, 1 \mathrm{H}), 8.60(\mathrm{t}, 1 \mathrm{H}), 8.77(\mathrm{~s}, 1 \mathrm{H}), 8.86(\mathrm{~d}, 1 \mathrm{H}) ;{ }^{13} \mathrm{C} \mathrm{NMR}$ $\delta=46.8,63.9,126.5,128.0,141.5,145.6,146.6,146.7$ (Figure S11).

\section{ASSOCIATED CONTENT}

\section{Supporting Information}

The Supporting Information is available free of charge on the ACS Publications website at DOI: 10.1021/acs.joc.7b02106.

Some MS and HPLC data, the protection by other pyridinium aldoximes against TCBQ-induced toxicity in HepG2, the reaction conditions to convert aldoximes to corresponding nitriles, and the relevant ${ }^{1} \mathrm{H}$ and ${ }^{13} \mathrm{C}$ NMR spectra (PDF)

\section{AUTHOR INFORMATION}

\section{Corresponding Author}

*E-mail: bzhu@rcees.ac.cn (B.-Z.Z.)

ORCID $\odot$

Balaraman Kalyanaraman: 0000-0002-9180-8296

Ben-Zhan Zhu: 0000-0001-5484-4290

Notes

The authors declare no competing financial interest.

\section{ACKNOWLEDGMENTS}

This research was supported by CAS grant (XDB01020300); NSFC Grants (21577149, 21477139, 21237005, 21621064, 21321004, and 21407163); NIH Grants ES11497, RR01008, and ES00210.

\section{REFERENCES}

(1) Song, Y.; Wagner, B. A.; Witmer, J. R.; Lehmler, H.-J.; Buettner, G. R. Proc. Natl. Acad. Sci. U. S. A. 2009, 106, 9725.

(2) Bolton, J. L.; Trush, M. A.; Penning, T. M.; Dryhurst, G.; Monks, T. J. Chem. Res. Toxicol. 2000, 13, 135.

(3) Zhu, B.-Z.; Shan, G.-Q. Chem. Res. Toxicol. 2009, 22, 969.

(4) Guyton, K. Z.; Loomis, D.; Grosse, Y.; El Ghissassi, F.; Bouvard, V.; Benbrahim-Tallaa, L.; Guha, N.; Mattock, H.; Straif, K. Lancet Oncol. 2016, 17, 1637.

(5) Gupta, S. S.; Stadler, M.; Noser, C. A.; Ghosh, A.; Steinhoff, B.; Lenoir, D.; Horwitz, C. P.; Schramm, K.-W.; Collins, T. J. Science 2002, 296, 326.

(6) Meunier, B. Science 2002, 296, 270.

(7) Sorokin, A.; Meunier, B.; Séris, J.-L. Science 1995, 268, 1163.

(8) Zhao, Y.; Qin, F.; Boyd, J. M.; Anichina, J.; Li, X.-F. Anal. Chem. 2010, 82, 4599 .

(9) Huang, R.; Wang, W.; Qian, Y.; Boyd, J. M.; Zhao, Y.; Li, X.-F. Anal. Chem. 2013, 85, 4520.

(10) Li, J.; Wang, W.; Moe, B.; Wang, H.; Li, X.-F. Chem. Res. Toxicol. 2015, 28, 306.

(11) Kiderlen, D.; Eyer, P.; Worek, F. Biochem. Pharmacol. 2005, 69, 1853. 
(12) Eyer, P. A.; Worek, F. In Chemical Warfare Agents: Toxicology and Treatment, $2^{\text {nd }}$ ed.; Marrs, T. C., Maynard, R. L., Sidell, F. R., Eds.; Wiley: New York, 2007; p 305.

(13) Jokanovic, M.; Prostran, M. Curr. Med. Chem. 2009, 16, 2177.

(14) Kalisiak, J.; Ralph, E. C.; Zhang, J.; Cashman, J. R. J. Med. Chem. 2011, 54, 3319.

(15) Mercey, G.; Verdelet, T.; Renou, J.; Kliachyna, M.; Baati, R.; Nachon, F.; Jean, L.; Renard, P.-Y. Acc. Chem. Res. 2012, 45, 756.

(16) Lee, J. Y.; Lee, Y. H.; Byun, Y. G. Phosphorus, Sulfur Silicon Relat. Elem. 2012, 187, 641.

(17) Sharma, R.; Gupta, B.; Sahu, A. K.; Acharya, J.; Satnami, M. L.; Ghosh, K. K. Chem.-Biol. Interact. 2016, 259, 85.

(18) Wei, Z.; Liu, Y.-q.; Wang, S.-z.; Yao, L.; Nie, H.-f.; Wang, Y.-a.; Liu, X.-Y.; Zheng, Z.-b.; Li, S. Bioorg. Med. Chem. 2017, 25, 4497.

(19) Sarr, D. H.; Kazunga, C.; Charles, M. J.; Pavlovich, J. G.; Aitken, M. D. Environ. Sci. Technol. 1995, 29, 2735.

(20) Dewangan, H. K.; Nagwanshi, R.; Ghosh, K. K.; Satnami, M. L. Catal. Lett. 2017, 147, 602.

(21) Zhu, B. Z.; Kalyanaraman, B.; Jiang, G. B. Proc. Natl. Acad. Sci. U. S. A. 2007, 104, 17575.

(22) Zhu, B.-Z.; Mao, L.; Huang, C.-H.; Qin, H.; Fan, R.-M.; Kalyanaraman, B.; Zhu, J.-G. Proc. Natl. Acad. Sci. U. S. A. 2012, 109, 16046.

(23) Li, F.; Huang, C.-H.; Xie, L.-N.; Qu, N.; Shao, J.; Shao, B.; Zhu, B.-Z. Sci. Rep. 2016, 6, 39207.

(24) Zhu, B.-Z.; Zhu, J.-G.; Mao, L.; Kalyanaraman, B.; Shan, G.-Q. Proc. Natl. Acad. Sci. U. S. A. 2010, 107, 20686.

(25) Lees, G.; Holmes, F.; Underhill, A.; Powell, D. J. Chem. Soc. A 1971, 337.

(26) Kammer, M. N.; Koplitz, L. V.; Mague, J. T. Acta Crystallogr., Sect. E: Struct. Rep. Online 2013, 69, o1281.

(27) Schroeder, A. C.; Digiovanni, J. H.; Von Bredow, J.; Heiffer, M. H. J. Pharm. Sci. 1989, 78, 132.

(28) Grob, C. Angew. Chem., Int. Ed. Engl. 1969, 8, 535.

(29) Gawley, R. E. In Organic Reactions; Kende, A. S., Paquette, L. A., Overman, L. E., Denmark, S. E., Eds.; Wiley: New York, 1988; Vol. 35, p 3.

(30) Pereira, M. M. A.; Santos, P. P. In The Chemistry of Hydroxylamines, Oximes and Hydroxamic Acids; Rappoport, Z., Liebman, J. F., Eds.; Wiley: New York, 2009; p 386.

(31) Drahl, M. A.; Manpadi, M.; Williams, L. J. Angew. Chem., Int. Ed. 2013, 52, 11222.

(32) Chandrasekhar, S. In Comprehensive Organic Synthesis II; Knochel, P., Molander, G. A., Eds.; Elsevier: Amsterdam, 2014; Vol. 7, p 770.

(33) De Luca, L.; Giacomelli, G.; Porcheddu, A. J. Org. Chem. 2002, 67, 6272.

(34) Shan, G.-Q.; Yu, A.; Zhao, C.-F.; Huang, C.-H.; Zhu, L.-Y.; Zhu, B.-Z. J. Org. Chem. 2015, 80, 180.

(35) Shao, J.; Huang, C.-H.; Kalyanaraman, B.; Zhu, B.-Z. Free Radical Biol. Med. 2013, 60, 177.

(36) Yin, R.; Zhang, D.; Song, Y.; Zhu, B. Z.; Wang, H. Sci. Rep. 2013, 3, 1269

(37) Zhu, B.-Z.; Har-El, R.; Kitrossky, N.; Chevion, M. Free Radical Biol. Med. 1998, 24, 360.

(38) Ribo, J. M.; Kaiser, K. L. Toxic. Assess. 1987, 2, 305.

(39) Witte, I.; Zhu, B.-Z.; Lueken, A.; Magnani, D.; Stossberg, H.; Chevion, M. Free Radical Biol. Med. 2000, 28, 693.

(40) Chignell, C. F.; Han, S. K.; Mouithys-Mickalad, A.; Sik, R. H.; Stadler, K.; Kadiiska, M. B. Toxicol. Appl. Pharmacol. 2008, 230, 17.

(41) Teuten, E. L.; Xu, L.; Reddy, C. M. Science 2005, 307, 917.

(42) Kelly, B. C.; Ikonomou, M. G.; Blair, J. D.; Morin, A. E.; Gobas, F. A. P. C. Science 2007, 317, 236.

(43) Gao, H.-Y.; Mao, L.; Li, F.; Xie, L.-N.; Huang, C.-H.; Shao, J.; Shao, B.; Kalyanaraman, B.; Zhu, B.-Z. Environ. Sci. Technol. 2017, 51, 2934.

(44) Chen, H.-M.; Lee, Y.-H.; Wang, Y.-J. Chem. Res. Toxicol. 2015, $28,339$.
(45) Zhao, B.; Yang, Y.; Wang, X.; Chong, Z.; Yin, R.; Song, S.-H.; Zhao, C.; Li, C.; Huang, H.; Sun, B.-F. Nucleic Acids Res. 2014, 42, 1593.

(46) Qin, H.; Huang, C. H.; Mao, L.; Xia, H. Y.; Kalyanaraman, B.; Shao, J.; Shan, G. Q.; Zhu, B. Z. Free Radical Biol. Med. 2013, 63, 459.

(47) Natoff, I. L.; Reiff, B. Toxicol. Appl. Pharmacol. 1973, 25, 569.

(48) Fukuto, T. R. Environ. Health Perspect. 1990, 87, 245. 